\title{
The diagnostic performance of patient symptoms in screening for COPD
}

\author{
Kate M. Johnson ${ }^{1}$ (D), Wan C. Tan², Jean Bourbeau ${ }^{3}$, Don D. $\operatorname{Sin}^{2,5}$, Mohsen Sadatsafavi ${ }^{1,4,5^{*}}$, for the Canadian Cohort \\ of Obstructive Lung Disease (CanCOLD) study and the Canadian Respiratory Research Network
}

\begin{abstract}
It is recommended that screening for COPD be restricted to symptomatic individuals, but supporting evidence is lacking. We determined the performance of wheeze, cough, phlegm, and dyspnea in discriminating COPD versus non-COPD in a population-based sample of 1332 adults. Area Under the Receiver Operating Curves (AUC) indicated that symptoms had modest performance whether assessed individually (AUCs 0.55-0.62), or in combination (AUC for number of symptoms as the predictor 0.64). AUC improved with the inclusion of multiple other factors (AUC 0.71). Restricting screening to symptomatic individuals is unlikely to substantially improve the yield of general population screening for undiagnosed COPD.
\end{abstract}

Keywords: Screening test, Population, Respiratory symptoms, Chronic obstructive pulmonary disease

\section{Introduction}

Chronic Obstructive Pulmonary Disease (COPD) is a common inflammatory lung condition that is characterized by symptoms of shortness of breath, cough, and sputum production [1]. Although COPD is under-diagnosed in the community [2], several major guidelines, including from the influential US Preventive Services Task Force, have recommended against the use of spirometry to screen for COPD in asymptomatic individuals in the general population because the number-needed-to-screen (NNS) to prevent adverse disease outcomes is prohibitively large [3, 4]. Some have advocated for case finding strategies to improve the diagnosis rate in the community in a more cost-effective manner, for example by targeting spirometry only among symptomatic individuals [5]. However, many patients with undiagnosed COPD have mild disease and may have few (if any) respiratory symptoms [6], and individuals without COPD can experience symptoms similar to those of COPD patients [7]. In addition, symptomatic COPD patients tend to be diagnosed earlier [6] and are therefore removed from the pool of cases that would be detected through a screening program. We

\footnotetext{
* Correspondence: msafavi@mail.ubc.ca

${ }^{1}$ Respiratory Evaluation Sciences Program, Collaboration for Outcomes

Research and Evaluation, Faculty of Pharmaceutical Sciences, University of British Columbia, Vancouver, Canada

${ }^{4}$ Centre for Clinical Epidemiology and Evaluation, Vancouver Coastal Health Institute, Vancouver, Canada
}

determined the diagnostic performance of patient symptoms for screening in the general population to assess whether the yield of screening could be improved by restricting it to the symptomatic population.

\section{Methods}

We used data from the Canadian Cohort of Obstructive Lung Disease (CanCOLD) Study. CanCOLD was a prospective cohort study of 1332 adults $\geq 40$ years who were sampled from the general Canadian population with multilevel sampling to ensure representativeness. Participants were followed for a maximum of 3 years with visits at 18-month intervals [8]. They reported their demographic information, smoking status and history, comorbidities, and respiratory symptoms at each visit using validated questionnaires. Diagnostic spirometry was performed at each visit and persistent airflow limitation was defined as post-bronchodilator $\mathrm{FEV}_{1} / \mathrm{FVC}<$ lower limit of normal. Participants were deemed to have undiagnosed COPD if they had persistent airflow limitation but did not report previous physician-diagnosed COPD, emphysema, or chronic bronchitis. Subjects with a previous diagnosis of COPD were excluded. Information was collected on the frequency or severity of cough, phlegm, and wheeze using three questions for each symptom. The responses were coded as a variable ranging from 0 to 3 for each symptom. Breathlessness was measured using the Medical 
Research Council dyspnea scale. We also assessed the total number of symptoms experienced by each participant (0-4 range).

First, we determined the independent associations between individual symptoms and the presence of undiagnosed COPD (v. no COPD) using a logistic regression model with symptoms as separate independent variables and adjusting for participant demographics, comorbidities, smoking status, and pack-years. Second, we assessed the diagnostic performance of symptoms when used individually to distinguish patients with undiagnosed COPD from non-COPD subjects. We evaluated the sensitivity and specificity of each symptom at different thresholds (i.e., $0,1,2$, or 3) for defining a patient as symptomatic. We fitted Receiver Operating Characteristic (ROC) curves to determine the Area Under the Curve (AUC) for each symptom individually, as well as their combined performance using the total number of symptoms. Finally, we used the AUC of the above-mentioned logistic regression model to assess the performance of all individual symptoms and covariates together. An AUC of 0.5 indicates the model has no discriminatory ability. Generalized estimating equations were used in all models to account for clustering of observations within individuals.

Ethics approval for CanCOLD was obtained from the relevant institutional review board at each study site. Written informed consent was obtained from all participants prior to study entry.

\section{Results}

The mean age of the sample was 67.4 years [SD 9.7], $44 \%$ were females, and $40 \%$ of the participants had three study visits. The overall prevalence of undiagnosed COPD was $26 \%$; $95 \%$ had mild to moderate disease based on the GOLD spirometric grading system [1]. The regression model indicated that reporting wheeze, dyspnea, and cough on most days were independently related to the presence of undiagnosed COPD (Table 1). However, symptoms alone had poor performance in identifying patients with undiagnosed COPD. Almost all symptoms, regardless of the severity, had sensitivities and positive predictive values less than $50 \%$ (Table 2).

If screening was applied to the general population (a "blind" screening approach), the NNS to detect one COPD case would be 3.8. If screening was restricted to individuals who reported symptoms, the NNS would be 3.0, but compared with the "blind" approach, an additional $17 \%$ of individuals with persistent airflow limitation would be missed.

The ROC curves indicated that wheeze had the best performance among all symptoms $(\mathrm{AUC}=0.62)$, followed by cough and dyspnea (each $\mathrm{AUC}=0.57$ ), and phlegm $(\mathrm{AUC}=0.55)$. The total number of symptoms performed marginally better than any symptom alone $(\mathrm{AUC}=0.64)$.
Table 1 Association between symptoms and other patient characteristics with the odds of having undiagnosed COPD (v. no COPD)

\begin{tabular}{|c|c|c|c|}
\hline & OR & $95 \% \mathrm{Cl}$ & $p$-value \\
\hline \multicolumn{4}{|l|}{ Cough } \\
\hline 1 (vs.0) & 1.08 & $0.86-1.36$ & 0.49 \\
\hline 2 (vs.0) & 1.38 & $0.93-2.04$ & 0.11 \\
\hline 3 (vs.0) & 1.35 & $1.09-1.68$ & 0.01 \\
\hline \multicolumn{4}{|l|}{ Wheeze } \\
\hline 1 (vs.0) & 1.34 & $1.03-1.73$ & 0.03 \\
\hline 2 (vs.0) & 1.74 & $1.38-2.20$ & $<0.01$ \\
\hline 3 (vs.0) & 1.77 & $0.93-3.38$ & 0.08 \\
\hline \multicolumn{4}{|l|}{ Phlegm } \\
\hline 1 (vs.0) & 1.21 & $0.89-1.66$ & 0.23 \\
\hline 2 (vs.0) & 1.35 & $0.77-2.36$ & 0.30 \\
\hline 3 (vs.0) & 1.24 & $0.93-1.65$ & 0.14 \\
\hline \multicolumn{4}{|l|}{ Dyspnea } \\
\hline 2 (vs.1) & 1.26 & $1.05-1.50$ & 0.01 \\
\hline 3 (vs.1) & 2.05 & $1.30-3.22$ & $<0.01$ \\
\hline 4 (vs.1) & 1.52 & $0.76-3.03$ & 0.24 \\
\hline 5 (vs.1) & 3.35 & $1.88-5.97$ & $<0.01$ \\
\hline $\mathrm{Age}^{\mathrm{a}}$ & 0.83 & $0.74-0.94$ & $<0.01$ \\
\hline Female (vs. male) & 1.03 & $0.81-1.30$ & 0.82 \\
\hline $\mathrm{BMI}^{\mathrm{a}}$ & 0.78 & $0.68-0.89$ & $<0.01$ \\
\hline Caucasian (vs. non-Caucasian) & 2.39 & $1.28-4.48$ & 0.01 \\
\hline \multicolumn{4}{|l|}{ Comorbidities } \\
\hline 1 comorbidity (vs. 0) & 0.93 & $0.76-1.14$ & 0.51 \\
\hline 2 comorbidities (vs. 0) & 0.75 & $0.48-1.18$ & 0.21 \\
\hline Smoking between visits (vs. no) & 1.16 & $0.96-1.41$ & 0.13 \\
\hline \multicolumn{4}{|l|}{ Smoking Pack-Years } \\
\hline $20-40$ (vs. < 20) & 2.09 & $1.53-2.86$ & $<0.01$ \\
\hline$>40$ (vs. <20) & 3.09 & $2.22-4.32$ & $<0.01$ \\
\hline
\end{tabular}

$B M I$ body mass index, $\mathrm{Cl}$ confidence interval, $O R$ odds ratio

${ }^{a}$ Variables were converted to $z$-scores in the regression model

AUC improved by $~ 0.06$ when each of the symptoms was combined with smoking history (measured as pack-years), resulting in an AUC of 0.67 for a model that included wheeze and pack-years. The model that included all individual symptoms and covariates improved the AUC to 0.71 (Fig. 1).

\section{Discussion}

Our results indicate that symptoms are relatively poor at discriminating undiagnosed COPD patients from nonCOPD subjects in a general population. The use of symptoms for screening is unlikely to significantly improve the diagnostic yield compared with "blind" screening in the general population. These data highlight the apparent paradox in finding strong associations between symptoms 
Table 2 Prevalence of each symptom severity category in the whole population ('Prev') across all study visits, and the prevalence of undiagnosed COPD ('COPD+') within that symptom severity category. Sensitivity ('TP'), specificity ('TN'), positive predictive value ('PPV'), and negative predictive value ('NPV') of each symptom when used alone to classify undiagnosed COPD (v. no COPD) using different severity thresholds

\begin{tabular}{|c|c|c|c|c|c|}
\hline \multirow[t]{2}{*}{ Symptom severity } & Cough $^{a}$ & Wheeze $^{b}$ & Phlegm $^{c}$ & Dyspnea $^{\mathrm{d}}$ & Total Symptoms ${ }^{\mathrm{e}}$ \\
\hline & Prev, COPD+ & Prev, COPD+ & Prev, COPD+ & Prev, COPD+ & Prev, COPD+ \\
\hline 0 & $72,23 \%$ & $78,21 \%$ & $83,24 \%$ & $70,23 \%$ & $45,17 \%$ \\
\hline 1 & $12,29 \%$ & $10,42 \%$ & $6,30 \%$ & $26,33 \%$ & $29,28 \%$ \\
\hline 2 & $3,35 \%$ & $10,49 \%$ & $1,47 \%$ & $3,56 \%$ & $16,33 \%$ \\
\hline 3 & $13,42 \%$ & $2,51 \%$ & $9,39 \%$ & $1,30 \%$ & $7,50 \%$ \\
\hline \multirow[t]{2}{*}{4} & & & & $<1,67 \%$ & $4,52 \%$ \\
\hline & $\begin{array}{l}T P, T N \\
P P V, N P V\end{array}$ & $\begin{array}{l}T P, T N \\
P P V, N P V\end{array}$ & $\begin{array}{l}T P, T N \\
P P V, N P V\end{array}$ & $\begin{array}{l}T P, T N \\
P P V, N P V\end{array}$ & $\begin{array}{l}T P, T N \\
P P V, N P V\end{array}$ \\
\hline 0 vs. $>0$ & $\begin{array}{l}37,76 \% \\
36,77 \%\end{array}$ & $\begin{array}{l}39,84 \% \\
46,79 \%\end{array}$ & $\begin{array}{l}24,85 \% \\
37,76 \%\end{array}$ & $\begin{array}{l}40,74 \% \\
35,77 \%\end{array}$ & $\begin{array}{l}71,50 \% \\
34,83 \%\end{array}$ \\
\hline$\leq 1$ vs. $>1$ & $\begin{array}{l}24,88 \% \\
41,76 \%\end{array}$ & $\begin{array}{l}23,91 \% \\
49,77 \%\end{array}$ & $\begin{array}{l}16,91 \% \\
40,75 \%\end{array}$ & $\begin{array}{l}7,98 \% \\
52,75 \%\end{array}$ & $\begin{array}{l}41,78 \% \\
40,79 \%\end{array}$ \\
\hline$\leq 2$ vs. $>2$ & $\begin{array}{l}21,90 \% \\
42,76 \%\end{array}$ & $\begin{array}{l}4,99 \% \\
51,74 \%\end{array}$ & $\begin{array}{l}14,92 \% \\
39,75 \%\end{array}$ & $\begin{array}{l}1,99 \% \\
38,74 \%\end{array}$ & $\begin{array}{l}21,93 \% \\
51,77 \%\end{array}$ \\
\hline$\leq 3$ vs. $>3$ & & & & $\begin{array}{l}<1,>99 \% \\
67,74 \%\end{array}$ & $\begin{array}{l}7,98 \% \\
52,75 \%\end{array}$ \\
\hline
\end{tabular}

Prev prevalence, COPD+ undiagnosed COPD, TP true positive (sensitivity), $T N$ true negative (specificity), $P P V$ positive predictive value, $N P V$ negative predictive value Patients were asked, since your last visit:

${ }^{a}$ 1) Do you usually cough when you don't have a cold? 1a) Are there months you cough most days? 1b) Do you cough most days for as much as 3 months? b) Have you had any wheezing or whistling in your chest? 2a) Do you only have wheezing or whistling when you have a cold? 2b) Have you had an attack of wheezing or whistling that made you short of breath?

'3) Do you usually have phlegm in your chest when you don't have a cold? 3a) Are there months you have phlegm most days? 3b) Do you hav e phlegm most days for as many as 3 months?

${ }^{\mathrm{d} S}$ Cores on the Medical Research Council (MRC) Dyspnea scale are subtracted by 1

'The sum of the number of individual symptoms that participants reported

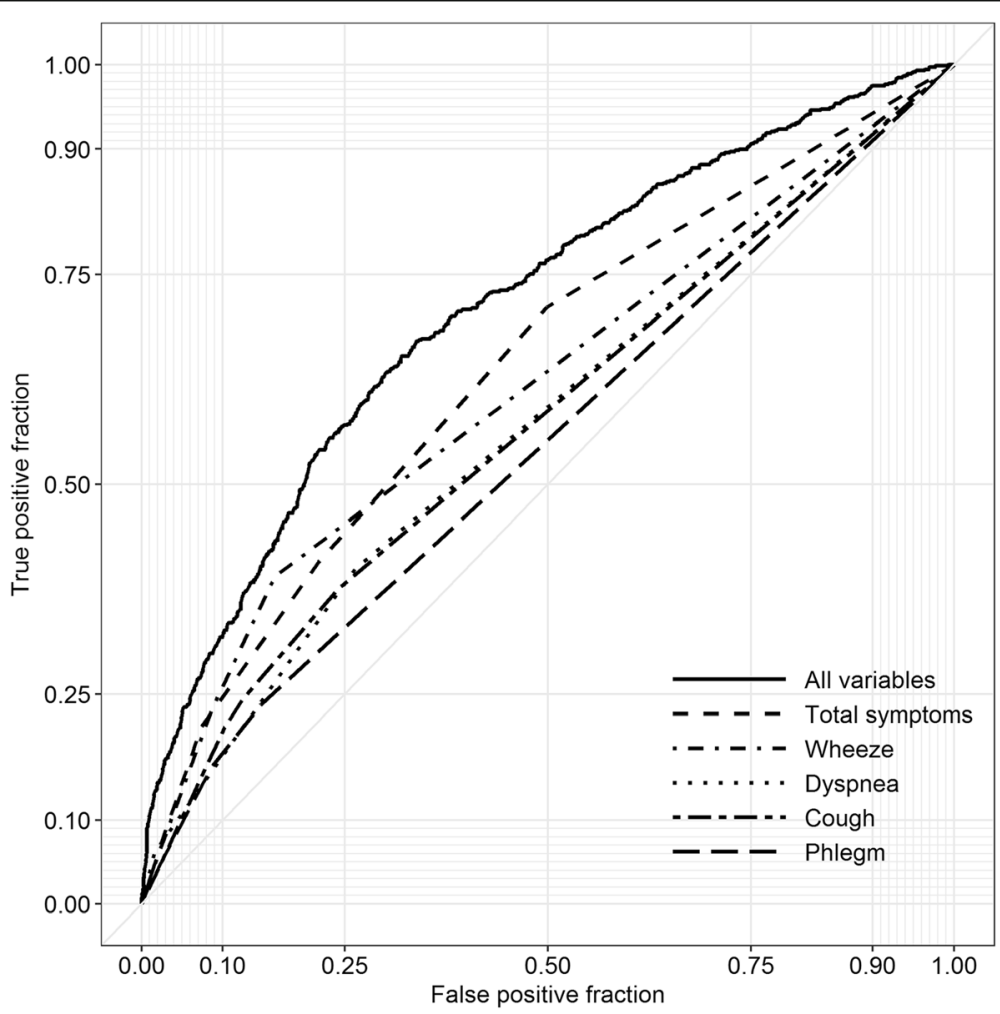

Fig. 1 Receiver operating characteristic (ROC) curves for a model with all of the symptoms and covariates included ('All variables'), as well as for each of the symptoms individually and the total number of symptoms reported by study participants ('Total symptoms') 
and undiagnosed COPD, yet poor diagnostic performance when symptoms are used to diagnose these "hidden" COPD cases. This observation is consistent with the well-established notion that a predictor can be strongly associated with an outcome while still being a poor classifier of that outcome [9]. Association models are useful for evaluating relationships at the population level, but classification models are more relevant to decisions at an individual level, specifically whether a test (e.g., the presence of a symptom) can detect the underlying disease state (e.g., undiagnosed COPD).

Previous studies have evaluated the merits of opportunistic case detection based on patient characteristics at the point of care $[10,11]$. They generally found that patient characteristics and symptoms have modest capacity in detecting undiagnosed COPD [10-12]. A unique feature of our study is its population-based sample, which provides new evidence on whether the yield of population-based screening can be improved if symptoms are considered in the inclusion criterion (e.g., through advertisements for referral of symptomatic individuals for lung function testing). Although the costs and benefits of early intervention between symptomatic and asymptomatic patients were not considered here, our results do not support the use of symptoms in "case finding" for COPD. Symptoms should be used in conjunction with other characteristics such as pack-years of smoking to improve the diagnostic performance. Future studies should evaluate the cost-effectiveness of this approach considering the long-term outcomes associated with earlier diagnosis of COPD.

\section{Abbreviations \\ AUC: Area Under the Curve; CanCOLD: Canadian Cohort of Obstructive Lung Disease; COPD: Chronic Obstructive Pulmonary Disease; FEV ${ }_{1}$ : Forced Expiratory Volume in 1 s; FVC: Forced Vital Capacity; GOLD: Global Initiative for chronic Obstructive Lung Disease; NNS: Number Needed to Screen; ROC: Receiver Operating Characteristic curves; SD: Standard Deviation}

\section{Acknowledgements}

The authors thank the men and women who participated in the study and individuals in the CanCOLD Collaborative Research Group.

Members of the CanCOLD Collaborative Research Group are as follows. Executive Committee: Jean Bourbeau (McGill University, Montreal, Canada); Wan C. Tan, J. Mark FitzGerald; Don Sin (UBC, Vancouver, Canada); Darcy Marciniuk (University of Saskatoon, Saskatoon, Canada); Dennis E. O'Donnell (Queen's University, Kingston, Canada); Paul Hernandez (Dalhousie University, Halifax, Canada); Kenneth R. Chapman (University of Toronto, Toronto, Canada); Robert Cowie (University of Calgary, Calgary, Canada); Shawn Aaron (University of Ottawa, Ottawa, Canada); F. Maltais (University of Laval, Quebec City, Canada). International Advisory Board: Jonathon Samet (Keck School of Medicine of USC, Los Angeles, CA); Milo Puhan (John Hopkins School of Public Health, Baltimore, MD); Qutayba Hamid (McGill University, Montreal, Canada); James C. Hogg (UBC James Hogg Research Center, Vancouver, Canada). Operations Center: Jean Bourbeau (PI), Carole Jabet, Palmina Mancino, (McGill University, Montreal, Canada); Wan C. Tan (co-Pl), Don Sin, Sheena Tam, Jeremy Road, Joe Comeau, Adrian Png, Harvey Coxson, Jonathon Leipsic, Cameron Hague (University of British Columbia James Hogg Research Center, Vancouver, Canada). Economic Core: Mohsen Sadatsafavi (University of British Columbia, Vancouver, Canada). Public Health Core: Teresa To, Andrea Gershon (University of Toronto, Toronto, Canada). Data Management and Quality Control: Wan C. Tan, Harvey Coxson (UBC, Vancouver, Canada); Jean Bourbeau, Pei Zhi Li, Zhi Song, Yvan Fortier, Andrea Benedetti, Dennis Jensen (McGill University, Montreal, Canada). Field Centers: Wan C. Tan (Vancouver PI),
Christine Lo, Sarah Cheng, Cindy Fung, Nancy Haynes, Junior Chuang, Licong Li, Selva Bayat, Amanda Wong, Zoe Alavi, Catherine Peng, Bin Zhao, Nathalie Scott-Hsiung, Tasha Nadirshaw (UBC James Hogg Research Center, Vancouver, Canada); Jean Bourbeau (Montreal PI), Palmina Mancino, David Latreille, Jacinthe Baril, Laura Labonté (McGill University, Montreal, Canada); Kenneth Chapman (Toronto PI), Patricia McClean, Nadeen Audisho (University of Toronto, Toronto, Canada); R. Cowie and B. Walter (Calgary PI), Ann Cowie, Curtis Dumonceaux, Lisette Machado (University of Calgary, Calgary, Canada); Paul Hernandez (Halifax PI), Scott Fulton, Kristen Osterling (Dalhousie University, Halifax, Canada); Shawn Aaron (Ottawa PI), Kathy Vandemheen, Gay Pratt, Amanda Bergeron (University of Ottawa, Ottawa, Canada); Denis O'Donnell (Kingston PI), Matthew McNeil, Kate Whelan (Queen's University, Kingston, Canada); François Maltais (Quebec PI), Cynthia Brouillard (Université Laval, Quebec City, Canada); Darcy Marciniuk (Saskatoon PI), Ron Clemens, Janet Baran (University of Saskatoon, Saskatoon, Canada).

\section{Funding}

The current study was funded by a Canadian Lung Association Breathing as One Studentship Award and the Canadian Institutes of Health Research (application number 142238). The Canadian Cohort Obstructive Lung Disease (CanCOLD) study is currently funded by the Canadian Respiratory Research Network (CRRN); industry partners: Astra Zeneca Canada Ltd.; Boehringer Ingelheim Canada Ltd;; GlaxoSmithKline Canada Ltd.; and Novartis. Researchers at RI-MUHC Montreal and Icapture Centre Vancouver lead the project. Previous funding partners are the CIHR (CIHR/Rx\&D Collaborative Research Program Operating Grants 93326); the Respiratory Health Network of the Fonds de la recherche en santé du Québec (FRSQ); industry partners: Almirall; Merck Nycomed; Pfizer Canada Ltd.; and Theratechnologies. The funders had no role in study design, data collection and analysis, or preparation of the manuscript.

\section{Availability of data and materials}

The data analysed in the current study are not publicly available but may be made available from the CanCOLD Research Group upon reasonable request.

\section{Authors' contributions}

WT and JB are co-Principal Investigators of the CanCOLD study. MS and KJ formulated the current study idea. KJ performed all data analyses and wrote the first draft of the manuscript. All authors contributed to interpretation of findings, critically commented on the manuscript and approved the final version. MS is the guarantor of the manuscript.

Ethics approval and consent to participate

Ethics approval for CanCOLD was obtained from the relevant institutional review board at each study site. Written informed consent was obtained from all participants prior to study entry.

\section{Consent for publication}

Not applicable.

\section{Competing interests}

The authors declare that they have no competing interests.

\section{Publisher's Note}

Springer Nature remains neutral with regard to jurisdictional claims in published maps and institutional affiliations.

\section{Author details}

${ }^{1}$ Respiratory Evaluation Sciences Program, Collaboration for Outcomes Research and Evaluation, Faculty of Pharmaceutical Sciences, University of British Columbia, Vancouver, Canada. ${ }^{2}$ Centre for Heart Lung Innovation (the James Hogg Research Centre), St. Paul's Hospital, Vancouver, Canada. ${ }^{3}$ Respiratory Epidemiology and Clinical Research Unit, McGill University, Montreal, Canada. ${ }^{4}$ Centre for Clinical Epidemiology and Evaluation, Vancouver Coastal Health Institute, Vancouver, Canada. Institute for Heart and Lung Health, Department of Medicine, The University of British Columbia, Vancouver, Canada. 
Received: 3 June 2018 Accepted: 26 July 2018

Published online: 03 August 2018

\section{References}

1. From the Global Strategy for the Diagnosis, Management and Prevention of COPD. Global Initiative for Chronic Obstructive Lung Disease (GOLD) [Internet]. 2017 [cited 2017 May 1]. Available from: http://goldcopd.org

2. Lamprecht B, Soriano JB, Studnicka M, Kaiser B, Vanfleteren LE, Gnatiuc L, et al. Determinants of underdiagnosis of COPD in national and international surveys. Chest. 2015;148:971-85.

3. Qaseem A, Wilt TJ, Weinberger SE, Hanania NA, Criner G, van der Molen T, et al. Diagnosis and management of stable chronic obstructive pulmonary disease: a clinical practice guideline update from the American College of Physicians, American College of Chest Physicians, American Thoracic Society, and European Respiratory Society. Ann Intern Med. 2011;155:179-91.

4. US Preventive Services Task Force (USPSTF), Siu AL, Bibbins-Domingo K, Grossman DC, Davidson KW, Epling JWJ, et al. Screening for Chronic Obstructive Pulmonary Disease: US Preventive Services Task Force Recommendation Statement. JAMA. 2016;315:1372-7.

5. Kaplan A, Thomas M. Screening for COPD: the gap between logic and evidence. Eur Respir Rev. 2017;26:160113.

6. Johnson KM, Bryan S, Ghanbarian S, Sin DD, Sadatsafavi M. Characterizing undiagnosed chronic obstructive pulmonary disease: a systematic review and meta-analysis. Respir Res. 2018;19:26.

7. Tan WC, Bourbeau J, Hernandez P, Chapman KR, Cowie R, FitzGerald JM, et al. Exacerbation-like respiratory symptoms in individuals without chronic obstructive pulmonary disease: results from a population-based study. Thorax. 2014;69:709-17.

8. Bourbeau J, Tan WC, Benedetti A, Aaron SD, Chapman KR, Coxson HO, et al. Canadian cohort obstructive lung disease (CanCOLD): fulfilling the need for longitudinal observational studies in COPD. COPD. 2014;11:125-32.

9. Pepe MS. Evaluating technologies for classification and prediction in medicine. Stat Med. 2005:24:3687-96.

10. Stanley AJ, Hasan I, Crockett AJ, van Schayck OCP, Zwar NA. COPD diagnostic questionnaire (CDQ) for selecting at-risk patients for spirometry: a crosssectional study in Australian general practice. NPJ Prim Care Respir Med. 2014:24:14024

11. Martinez FJ, Raczek AE, Seifer FD, Conoscenti CS, Curtice TG, D'Eletto T, et al. Development and initial validation of a self-scored COPD population screener questionnaire (COPD-PS). COPD J Chronic Obstr Pulm Dis. 2008:5:85-95.

12. Gershon AS, Hwee J, Chapman KR, Aaron SD, O'Donnell DE, Stanbrook MB, et al. Factors associated with undiagnosed and overdiagnosed COPD. Eur Respir J. 2016:48:561-4.

Ready to submit your research? Choose BMC and benefit from:

- fast, convenient online submission

- thorough peer review by experienced researchers in your field

- rapid publication on acceptance

- support for research data, including large and complex data types

- gold Open Access which fosters wider collaboration and increased citations

- maximum visibility for your research: over $100 \mathrm{M}$ website views per year

At $\mathrm{BMC}$, research is always in progress.

Learn more biomedcentral.com/submissions 